\title{
APRENDER A CONHECER: saber é desejar aprender o que não se sabe
}

\section{Learn to know: know is to desire the learning of what is not known}

Dimas Floriani*

\section{Resumo}

Este texto busca localizar as conexões do conhecimento com o mundo na dimensão do processo social de sua construção. Entende-se que numa sociedade do conhecimento, não saber aprender é desconhecer. São 13 as razões enunciadas: os pontos cegos, as fragilidades lacunares do não saber, o reconhecimento dos limites, das possibilidades do próprio conhecimento e daquilo que está ao seu alcance.

Palavras-chave: Conhecimento, Aprendizagem, Sociedade da informação, Produção do conhecimento.

\section{Abstract}

This text searchs to locate the connections of the knowledge with the world in the social process dimension of its construction. It understands that in a knowledge society, not knowing to learn is not to know. There are the 13 enunciated reasons: considering the blind points, the fragilities lacunars of here not knowing, the limits recognition, the proper knowledge possibilities and of that is to its range.

Keywords: knowledge, Leaming, Information Society, Knowledge Production.

* Doutor em Sociologia (UCL-Bélgica). Professor na graduação e mestrado em Sociologia e no Doutorado Interdisciplinar em Meio Ambiente e Desenvolvimento da UFPR. Autor de diversos trabalhos recentes sobre epistemologia ambiental e interdisciplinaridade e meio ambiente. Universidade Federal do Paraná - UFPR - Educação

Rua XV de Novembro, 1299, Centro, Curitiba - PR, CEP 80060-150.

E-mail: floriani@ufpr.br 
Há tantas maneiras interessantes de querer saber o que não se sabe, de acordo ao desejo de saber. Isso resume as tentativas de querer aprender a conhecer. Em uma sociedade do conhecimento, não saber aprender é desconhecer. Mas informação não significa necessariamente conhecimento, muito embora as sociedades contemporâneas produzissem conhecimento pela informação e vice-versa.

São 13 as razões enunciadas aqui, levando-se em conta o desconhecimento do mundo (os pontos cegos e as fragilidades lacunares do não saber), assim como o reconhecimento dos limites e das possibilidades do próprio conhecimento e daquilo que está a seu alcance, isto é, pelo viver efetivo e pela possibilidade de viver: "Quando digo que conhecer é viver e viver é conhecer, o que estou dizendo é que o ser vivo, no momento em que deixa de ser congruente com sua circunstância, morre" (MATURANA, 2001).

Mas o conhecer não se conforma com a cognição acerca do mundo, não fosse o sentido que esse processo implica. O conhecimento é uma forma de reconhecimento do mundo, obtidos pela comunicação humana, pela rede de sentidos construídos e negociados (disputados) socialmente.

Neste texto, buscou-se localizar as conexões do conhecimento com o mundo, na dimensão do processo social de sua construção.

1. O que é efetivamente aprender, em uma sociedade da informação e do conhecimento? Aprender é, antes de qualquer coisa, a possibilidade de reavaliar constantemente o conjunto de informações. Estas, por sua vez, são passíveis de reformulações no contexto de sua produção e, portanto, objeto permanente de modificações.

Sabe-se, contudo, que nem sempre se consegue tomar consciência de como e o que se aprende, porque ocorre uma certa automação nos processos de ensino-aprendizagem. Quem ensina pode ser também vítima de seu próprio objeto de aprendizado: pela inércia de aprender e ensinar, pela indiferença que se exerce sobre os conteúdos desse transmitir. Daí que dificilmente se aprende o que não se ama e dificilmente se aprende o que não se gosta. $O$ que não se gosta e, portanto, se desconhece, pode transformar-se em algo que se odeia.

Aprender é a possibilidade de se criar uma expectativa sobre um futuro aprender; é desejar saber o que não se sabe. Aprender é um desejo de saber sobre o que não se sabe.

2. Desde cedo, registramos dados, informações, enfim, computamos e cogitamos. Os seres vivos, de maneira geral, computam informações, sem necessariamente pensar (cogitar) sobre elas. Este é o primeiro grande diferencial entre os seres vivos que possuem sistema nervoso e simbólico (linguagem 
desenvolvida) como os humanos e outros seres não-humanos (embora também complexos). Outra característica importante entre os seres humanos e os não-humanos é que os primeiros tendem a aprender indefinidamente dos erros que cometem, enquanto que para os segundos os erros podem ser obstáculos intransponíveis. A programação genética de certos animais já traz praticamente definidos os mecanismos de reprodução das condições de vida de certas espécies (a fabricação de colméias, de ninhos, de formigueiros, etc.). Contudo, não se sabe tudo sobre os limites de aprendizado dos animais. Rupert Sheldrake (2000), por exemplo, refere-se a novos aprendizados de pombos e de chimpanzés, desde que o contexto lhes apresente novidades.

Contudo, podem-se questionar alguns erros humanos, incorrigíveis, os quais não seriam suficientes para fazer com que os seres humanos aprendam. Há erros que, repetidos, tornam cegas as próprias condições do aprendizado humano. É o caso das guerras.

Na maioria das sociedades animais, não ocorre o extermínio deliberado das espécies como pode ou tende a ocorrer entre a espécie humana. Mata-se e morre-se por motivos ditos nobres (convicções religiosas, políticas, culturais, ou por falta dessas crenças). Mata-se e morre-se também por motivos fúteis.

3. Os seres humanos fazem parte, talvez, da única espécie que se interessa pelas condições de aprendizado; que se lança questão sobre porque pensa, fala e aprende, além de indagar-se sobre as dificuldades de se aprender. É talvez uma das poucas espécies que mais demora, desde que nasce, a favorecer a autonomia dos indivíduos. É provável que esse elevado grau de dependência à mãe e ao grupo primário (família) tenha, desde o início da vida extra-uterina, gerado profundas contrapartidas de desenvolvimento da inteligência, da fala e das habilidades práticas. Aquilo que poderia ser sua debilidade na origem é, posteriormente, sua fortaleza, isto é, reforça a necessidade de uma proteção coletiva, mediante o núcleo natural (família) e os processos de interação social.

Antropólogos e paleontólogos que estudaram os comportamentos dos hominídeos primitivos da África descrevem as atitudes oportunistas e as estratégias de cálculo do homo sapiens, ao esperarem que os animais mais poderosos (leões e tigres, por exemplo) largassem os restos de suas presas em campo aberto, para descerem das árvores e se alimentarem da caça restante. Talvez aí residissem os indícios primitivos do senso de oportunidade ou do oportunismo humano.

4. A divisão social do trabalho concorreu para diversificar os símbolos, os objetos produzidos, o conhecimento que os seres humanos foram ad- 
quirindo, no acúmulo de suas experiências, aprendendo a armazenar informações essenciais, aguçando a arte e o ofício de conservação e transmissão transmutadora dessas experiências intra e intergeracionais. Da caverna, nas quais se imprimiam os signos rudimentares, ao computador, que registra signos virtuais e passageiros, transformaram-se as condições materiais da comunicação, além dos motivos e dos objetivos da comunicação. $O$ mesmo se pode dizer da condição humana. Mesmo que o sentido do humano tenha assumido distintas configurações ao longo das transformações socioculturais, os sentimentos (amor, ódio, paixão, alegria, tristeza, esperança) são os mesmos, embora se transformem culturalmente. Uma obra ou uma representação de arte pode comover tanto gregos clássicos, como aborígines, ou sociedades do renascimento e da modernidade tardia. Os sentimentos estão nos fundamentos das emoções culturalmente transfiguradas. Por outro lado, se todas as sociedades humanas necessitam apropriar-se da natureza para reproduzir suas condições materiais de vida, seria de se esperar, como desejável, o modelo desenfreado de produção e de consumo, típicos do capitalismo globalizado?

5. O conhecer tornou-se objeto de ensino-aprendizado. As sociedades crescentemente tecnicizadas e altamente cientificizadas impõem um tempo cada vez maior para a aquisição de habilidades técnico-profissionais, sem garantir, contudo, emprego para todos os seus aprendizes. O conhecimento tornou-se ofício obrigatório, sem a necessária contrapartida da auto-realização daqueles que empreendem o duro caminho do aprendizado. Ao tornar-se técnico, o conhecimento descarta a possibilidade de se conhecer desinteressadamente, pelo prazer de conhecer o desconhecido.

Essa especialização de saberes parciais segmentou a árvore do conhecimento em ramos que desconhecem o tronco comum do qual fazem parte. A natureza é apreendida como algo estranho, exterior e distante da vida humana, mediada pela tecnologia e artificializada em sociedade. Tudo deve ser convertido em valor agregado, para ser reconhecido pelo mercado. Nada pode ser fortuito, espontâneo e desinteressado.

6. Sociedades e saberes tradicionais são mal vistos, pois estão de fora do círculo do progresso material das sociedades modernas. Não têm nada a ensinar às mais avançadas; ao contrário, deverão percorrer o caminho do progresso, tal qual foi trilhado pela urbanização e industrialização. Esta é a ideologia da modernidade. Porém, não há ilusão que dure eternamente, mesmo aquela apoiada em realidades concretas e visíveis, como as economias de mercado.A economia de mercado poderia ser viável (poderia?), desde que não marginalizasse a diversidade cultural e impusesse unilateralmente o monopólio da produção e do consumo sobre todas as esferas da vida humana e 
da natureza. Bastasse, para isso, que se instaurasse a convivência de culturas e civilizações, que se valorizassem as longas e profundas experiências dos saberes indígenas e camponeses, de formas de vida e de experiências multiculturais, que se privilegiasse a ética da sustentabilidade, contrária aos diversos extermínios instituídos pela modernidade: o extermínio das culturas humanas estranhas às lógicas do mercado, da biodiversidade, das florestas, dos rios, dos recursos naturais não renováveis...

7. A produção do conhecimento é um território contestado e contestável. Autores e sociedades se disputam pela produção de discursos e de sentidos. Pode-se entender que essa produção é global e local simultaneamente. Mas por outro lado, essa mesma reunião apresenta-se, em muitas circunstâncias, dissociada, pois obedece a temporalidades diferenciadas. Por um lado, a localidade é velozmente expropriada, ao perder significação como lugar de uma economia ou de cultura autônoma e auto-suficiente; por outro, a globalização consuma uma progressiva separação do poder e da política. $\mathrm{O}$ capital flui de tal maneira que fagocita os espaços enquanto que a política continua como antes, local e territorial. Mais do que fim da história, seria o fim da geografia? Neste sentido, tanto o capital como o conhecimento se independizaram do confinamento local (FLORIANI, 2003; BAUMAN, 2001).

8. A modernidade é o reino da informação e do ruído. A 'sociedade do conhecimento' opera como insumo da própria produção que agencia formas de organização e de ordenamento do mundo, em termos materiais e simbólicos. Porém, não aboliu o reino da ambigüidade e, justamente por isso, instaura uma tensão permanente entre ocultamento/desvendamento, entre informação e desinformação. Sendo uma sociedade que produz 'ruído', há uma inflação de sentidos sobre o mundo, pois o mercado produz independentemente das necessidades subjetivas. A noção de 'necessidade' tornou-se um autômata a exemplo dos mercados. Estamos diante daquilo que Agnes Heller (1998) chamaria de reino da 'contingência'. Somos contingentes e isso é uma condição da modernidade. Mas essa contingência é uma imposição do próprio modo de funcionar do mundo das mercadorias, cuja provisoriedade se traduz em expectativas sempre renováveis. Uma vez mais, o domínio da ambigüidade se impõe como linguagem: a contingência torna-se necessidade, o provisório permanente.

9. Conhecimento e desconhecimento do mundo podem estar associados ao risco. Porque a sociedade produz informação e conhecimento em demasia, não significa que todas as pessoas e as sociedades globais saibam ou tenham consciência da ocorrência de uma série de fenômenos: políticos, eco- 
nômicos, tecnológicos, ambientais, culturais, etc. Há um desequilíbrio entre informações práticas imediatas e aquelas que se referem ao funcionamento das estruturas da sociedade e da natureza. As pessoas imaginam o mundo e suas vidas, de acordo a algumas representações dos programas televisivos e a outros 'aparelhos ideológicos' (religião, grupos primários e secundários, etc.). A possibilidade de se recodificar essas informações tem a ver com a capacidade dos indivíduos de desconstruir os sentidos manifestos e latentes desses códigos. Determinadas informações sobre estilos de vida, atitudes diante da natureza e outros valores estarão condicionadas por essa capacidade ou possibilidade de se reinterpretar o mundo. Estamos diante de uma das questões centrais das sociedades contemporâneas, isto é, se além de sua capacidade de gerarem informação e produzirem conhecimento, conseguem traduzi-los em práticas efetivas de cidadania e organização democrática, redundando em ganhos e em acesso aos bens civilizatórios (educação, renda, equilíbrio socioambiental, enfim, inclusão social).

10. Há uma produção incessante, em escala planetánia, de conhecimento em todos os horizontes possíveis, tanto pelas agências especializadas de conhecimento quanto pelas agências midiáticas. Segundo Gilddens (1989), aqui talvez coubesse a categoria de 'reflexividade', para tornar visível e operacional essa mútua função da informação/conhecimento. Próxima a essa categoria aparece outra, mais concreta e aplicável no campo da produção artística e da indústria cultural e do 'show business', a de "negociação da diversidade".

Tanto as exposições como as revistas de arte influenciam a autopercepção dos artistas bem como os critérios dos públicos assistentes.

A produção da informação/conhecimento pertence ao campo simbólico da produção-consumo e às disputas de significação/ressignificação da realidade.

11. Não se podem desconsiderar os interesses que rondam e orientam a produção do conhecimento científico, uma vez que este é produzido pela própria 'sociedade do conhecimento', inserida nas dinâmicas do mercado capitalista.

Acossadas cada vez mais por interesses empresariais privados, algumas áreas da pesquisa científica (biomédicas, biotecnológicas, engenharia genética, microeletrônica, entre as mais requisitadas) se encontram no meio do "conflito de interesses", a exemplo da economia, da política, do direito, da ética, da religião, do meio ambiente, dentre outras esferas da sociedade.

Essas disputas em torno do papel da ciência e da tecnologia se expressam no debate sobre a natureza da produção social do conhecimento, a sua finalidade e sentido para as sociedades e os indivíduos. De forma geral, politizam a relação entre o 'público' (uma ciência que possa interessar e beneficiar a todos, embora não livre de pressões dos interesses particulares e mer- 
cantis) e o 'privado' (a orientação da pesquisa apenas para áreas que signifiquem retorno financeiro para os investidores).

12. Se o critério para julgar o entendimento do mundo passa pelo crivo do conhecimento científico é porque a modernidade é devedora dessa forma de medir e de instrumentalizar a realidade. Seria a ciência, em si, a vilã da racionalidade, cuja maneira de ordenar, classificar e dispor os objetos de conhecimento torna-se surda diante de outras formas de saberes e de questionamentos do mundo?

A racionalidade que opera com a relação meios e fins e que busca instrumentalizar o mundo de forma unívoca, autoritária e excludente, advém de um imperialismo da razão, que subordina tudo ao cálculo da rentabilidade e do mercado. À medida que o conhecimento científico se retrai para trincheiras dos objetos de conhecimento fragmentados e isolados uns dos outros; à medida que se subordina cultural e economicamente aos mecanismos de mercado; à medida que substitui a pergunta "para que e para quem serve a ciência?" pela resposta "a ciência tem que ser viável em termos de mercado, não importando a finalidade nem o destinatário", então sim, o conhecimento científico torna-se prisioneiro de uma racionalidade que não é apenas unicamente da razão, mas da economia, da política e da cultura, isto é, de se fazer ciência nos moldes do mercado. O conhecimento científico, hegemonizado pelo mercado, tende, então, a tornar-se incapaz de produzir sua própria crítica, a partir de seus próprios critérios de racionalidade científica.

A ciência, ao apresentar-se como a forma dominante de explicação do mundo, torna-se uma ideologia. Ela parece combater ilusões, mas às vezes é incapaz de combater suas próprias ilusões. Ela se tornou uma das principais forças produtivas das sociedades modernas, institucionalizando-se e tornando-se a principal forma de organização. A ciência tornou-se uma forma cultural de representar e controlar o mundo. A crise das sociedades atuais, nessa perspectiva, não é apenas de destruição pela instrumentalidade técnica. É uma crise da racionalidade, do entendimento segmentado do mundo. Rupert Sheldrake (1995) falará da necessidade de ampliar o sentido da ciência. Isso implica, como contrapartida, novos fazeres. Ao produzir-se a si mesma, a ciência não olha para si mesma. Ela revela também outras intenções filosóficas e culturais de nosso tempo. Neste sentido, a ciência torna-se problemática em termos de suas próprias premissas (FLORIANI, 2001).

13. Se a política é o espaço de disputas de poder e de disposição do governo das coisas e da gerência das sociedades; e que esse espaço é um espaço aberto, de crítica e de conflito permanente e em constante construção, então é possível pensar na inclusão de outras racionalidades e de outros sabe- 
res, mediante a disputa da produção simbólica do mundo. Enfim, essa disputa de sentidos e de ressignificações do mundo aparece como uma busca permanente e como possibilidade de construção de outras racionalidades discursivas e de outras formas de atuar em sociedade e na natureza.

A idéia de ciência acabou ampliando seu sentido e seu alcance para diversas esferas de produção do conhecimento. Essa difusão de sentido pode, contudo, abrir espaços para uma negociação entre superfícies discursivas mesmo que contraditórias. Não se trata de unificar o conhecimento sobre a natureza ou a sociedade em um único conhecimento. Às vezes, o holismo pode descambar em perniciosa metafísica e a totalidade em totalitarismo do pensamento.

Deve-se, ao contrário, fustigar o conceito de racionalidade científica, convidando-a a negociar com outras racionalidades, e abrindo-a para um diálogo de saberes (LEFF, 2001). Para se chegar a uma hibridação de saberes, necessita-se de uma nova epistemologia que não dependa apenas dos cânones do saber científico, mas também da constelação de diversidades arraigadas na cultura e na identidade. Trata-se de uma complexidade ambiental que busque demarcar os conflitos ecológicos e a crise ambiental em um espaço outro que o da administração científica da natureza.

\section{Referências}

BAUMAN, Z. En busca de la política. Ciudad Del México: Fondo de Cultura Económica, 2001.

DEMO, P. Educação e conhecimento: relação necessária, insuficiente e controversa. Petrópolis: Vozes, 2000.

FLORIANI, D. Conhecimento científico: racionalidade instrumental e cultura. Jornal da Ciência: SBPC, Rio de Janeiro, RJ, p. 14, 2001.

[s. n.], 2003.

. Conhecimento, meio ambiente e globalização. No prelo. Curitiba:

GARCÍA, Canclini, N. La globalización imaginada. Ciudad Del México: Paidós, 1999.

GIDDES, A. A Constituição da sociedade. São Paulo, SP: Martins Fontes, 1989.

HELLER, A. ; FEHÉR, F. A condição política pós-moderna. Rio de janeiro, RJ: Civilização Brasileira, 1998. 